\title{
A TRADIÇÃO ESQUECIDA Estudo sobre a sociologia de Antonio Candido
}

\section{Luiz Carlos Jackson}

A pesquisa foi feita com enorme sacrificio pessoal e a elaboração do livro foi lenta e exigente. Por seu intermédio, um tipo de homem pobre "livre" ganhou espaço na estante dos clássicos. Iluminou-se uma parcela do Brasil dos de baixo, o que eles são, como gente e portadores de uma civilização excluida e de uma sociedade subalternizada. [...] Descritos e interpretados como uma totalidade, eles configuram os parceiros que não são ouvidos e ganharam, por meio do livro, presença bistórica nos subterrâneos de uma sociedade civil em tensão com o que ela não é mas deveria ser.

(Fernandes, 1992, p. 35)

O Crítico - Não estou contente com seus últimos livros. A rigor aceito que o sociólogo e o filósofo precisam se esforçar para serem entendidos por todo mundo; que atenuem suas pesquisas e escondam todo o material sobre o qual repousa seu edificio, seus trabalbos pacientes de aproximação, suas fichas documentárias, suas elaborações esta- tísticas. Mas, noto no senhor uma tendência mais grave - fazer da poesia um método de sociologia.

(Bastide, 1983, p. 8)

A trajetória intelectual de Antonio Candido é profundamente ligada à história das Ciências Sociais na $\mathrm{FFCL} / \mathrm{USP},{ }^{1}$ onde realizou sua graduação (1939-1941) e tornou-se professor assistente de Fernando de Azevedo na Cadeira de Sociologia II (1942-1958). Afastado institucionalmente da sociologia e consagrado como crítico literário, a importância do autor na sociologia brasileira deve ser resgatada em justa medida, para que se evitem os extremos do esquecimento e da apologia. O texto a seguir toma como ponto de partida a íntima relação entre literatura, crítica e sociologia ${ }^{2}$ na obra do autor e avalia em particular o significado de Os parceiros do Rio Bonito na formação da sociologia paulista e brasileira. 
Apresentado como tese de doutorado em 1954 e publicado dez anos mais tarde por José Olympio na coleção "Documentos Brasileiros", Os parceiros do Rio Bonito é a contribuição mais importante de Antonio Candido à sociologia brasileira. $^{3}$ A pesquisa e a escritura desse livro aconteceram praticamente ao mesmo tempo em que o autor escreveu Formação da literatura brasileira. ${ }^{4}$ Esta "coincidência" sugere uma questão pouco explorada: a relação da sociologia com a crítica literária na obra de Antonio Candido. Aparentemente, a produção especificamente sociológica, cujo núcleo é Os parceiros do Rio Bonito, não tem ligação estreita com a crítica. Nossa primeira hipótese afirma o contrário: apesar da evidente distância temática, as duas obras respondem de forma diferenciada à mesma preocupação, apontando para uma unidade interna à diversidade de sua produção que a vinculam a problemas típicos de uma tradição específica do pensamento brasileiro.

A primeira hipótese relaciona-se à segunda: Os parceiros do Rio Bonito não é apenas uma monografia antropológica (ou um estudo de comunidade), mas uma interpretação abrangente de nossa formação social. A afirmação deve ser matizada, pois o livro descreve a vida de um grupo de parceiros na fazenda Bela Aliança, situada no pequeno município de Bofete, no interior de São Paulo. É a partir do parceiro de Bofete, entretanto, que Antonio Candido recupera a formação histórica da cultura caipira no Estado de São Paulo, e com ela a tradição esquecida da formação social brasileira.

É conhecida a leitura de Paulo Arantes e Roberto Schwarz, que enquadra a obra máxima de Antonio Candido, Formação da literatura brasileira (cuja redação não teve motivação acadêmica), na tradição dos mais importantes ensaios histórico-sociológicos das décadas de 30 e 40: Casa- grande E senzala, de Gilberto Freyre; Raizes do Brasil, de Sérgio Buarque de Holanda e Formação do Brasil contemporâneo, de Caio Prado Jr. Tais estudos, indefinidos entre história, sociologia e literatura, interpretam o processo de formação da nação e do Estado brasileiro. De maneira análoga, Formação da literatura brasileira descreve a formação literária - seguindo neste aspecto a tradição de críticos como Sílvio Romero e José Veríssimo - como momento necessário ao mesmo processo.

Não há por que duvidar, a intenção está no título. No caso de Os parceiros do Rio Bonito, tese de doutorado apresentada à cadeira de Sociologia II na Faculdade de Filosofia Ciências e Letras da USP, há motivos de sobra para tanto, uma vez que entre esse livro e as grandes interpretações do Brasil, verifica-se na sociologia paulista um esforço de superação dessa perspectiva, identificada com o Brasil arcaico e conservador. De fato, os trabalhos realizados na USP e na Escola Livre de Sociologia e Política a partir da década de 40 transformaram o padrão dos estudos sobre a sociedade brasileira, conforme o depoimento de Antonio Candido:

A importância da Sociologia e Política e da Faculdade foi deslocar a sociologia brasileira das classes dominantes para as classes dominadas. Os grandes nomes da sociologia brasileira eram Gilberto Freyre e Oliveira Vianna, que estudavam as classes dominantes, na perspectiva da história. A realidade imediata do Brasil contemporâneo foi estudada pela Escola de Sociologia e pela Faculdade em suas camadas humildes. Samuel Lowrie fez a pesquisa sobre o lixeiro; Gioconda Mussolini estudou os caiçaras; eu estudei o parceiro rural; Egon Schaden, o índio destribalizado; Florestan, o negro. Por assim dizer, nós radicalizamos a sociologia brasileira" (depoimento concedido em 30/09/1996).

Apesar de distanciar-se do ensaísmo, ao lado dos autores citados, todos vinculados à então recente experiência acadêmica paulista, Os parceiros do Rio Bonito aproxima-se ao sugerir uma interpretação ampla da formação social brasileira a partir da colonização paulista, iniciada no século XVI. Nesse sentido, pode ser lido dentro da longa tradição do pensamento social brasileiro, mas especialmente ao lado de autores como Euclides da Cunha, Gilberto Freyre, Sérgio Buarque de Holanda e Caio Prado Jr.

Em Os parceiros do Rio Bonito, a argumentação de Antonio Candido percorre diferentes níveis, articulados a partir da etnografia realizada em Bofete. Destacamos aqui sua preocupação his- 
tórica, evidente na primeira parte do livro. O livro foi recebido inicialmente como trabalho de cunho antropológico, dos primeiros a estudar de perto e sistematicamente a cultura das populações camponesas no Brasil. O grupo estudado habitava a fazenda Bela Aliança, em Bofete, onde Edgard Carone viveu por doze anos, entre 1948 e $1960 .{ }^{5} \mathrm{Na}$ época, a fazenda, que produzira café até o princípio do século, estava voltada para a produção de gêneros de subsistência. O principal regime de trabalho era a parceria. ${ }^{6}$ Preocupado com as transformações da sociedade caipira diante do fenômeno da urbanização, Antonio Candido escolhe o parceiro como objeto da pesquisa etnográfica porque ele seria uma espécie de ponto médio entre o caipira, sitiante autônomo, e o trabalhador assalariado. O objetivo explícito era buscar elementos que permitissem entender a assimilação do caipira pela sociedade abrangente. Mas o livro apresenta, também, uma reconstrução histórica do "mundo" caipira desde os primórdios da colonização em São Paulo, colonização singular porque, desde o século XVI, esteve voltada para a penetração do interior.

No prefácio de 1964, Antonio Candido aponta as influências intelectuais que atuaram diretamente na elaboração do trabalho. São citados os seguintes autores estrangeiros: Marx, Redfield, Audrey Richards, Malinovski, Lévi-Strauss. O autor brasileiro referido é Sérgio Buarque de Holanda, cujos trabalhos citados são Monções e "Índios e mamelucos na expansão paulista". A "presença" de Marx, restrita à teoria da história da Ideologia alemã, afirma a preocupação histórica em Os parceiros do Rio Bonito, e direciona a análise para a produção dos meios de vida.

Quanto às críticas que, ouvi dizer, alguns faziam a respeito de eu ter misturado autores tão díspares, penso que não cabem, porque toda tentativa de síntese parte necessariamente de elementos díspares. O importante é chegar a um ponto de vista integrado, harmonioso e realmente explicativo. Quero ainda esclarecer que sofri muita influência de Marx, mas nunca me considerei marxista propriamente dito, obrigado a ser coerente com a totalidade de sua filosofia. E, pensando bem, Marx também poderia sofrer reparos pelo fato de haver misturado Hegel, Ricardo, Adam Smith, Malthus, economistas liberais e socialistas franceses (depoimento concedido em 06/06/1996)

A etnografia realizada em Bofete é o principal método de trabalho. Sua importância é central, pois permite a reconstrução histórica da vida caipira tradicional com depoimentos de velhos caipiras, ao mesmo tempo em que fornece dados para a compreensão da vida do agrupamento de parceiros estudado, e a transformação da cultura caipira em geral. ' Como fontes históricas escritas, são utilizados relatos de viajantes do século XVIII e XIX, além de autores folcloristas do começo do século, como Amadeu Amaral e Cornélio Pires. O trabalho é caracterizado pelo autor como resultado "de certas orientações do antropólogo a outras mais próprias do sociólogo”, (Candido, 1971, p. 17) o que significa combinar a descrição detalhada de um universo particular com as generalizações exigidas pela análise sociológica, ${ }^{8}$ aqui preocupada com a assimilação da sociedade caipira pela capitalista abrangente, como já foi dito.

O livro não apresenta somente uma análise objetiva e imparcial, como os de Emílio Willems e Donald Pierson: "procuro localizar um aspecto da vida social [...] considerado não só como tema sociológico, mas também como problema social" (Candido, 1971, p. 20). Sugere uma proposta política: a reforma agrária, orientada por estudos sobre a cultura e a sociabilidade das populações rurais. A análise, comprometida com os problemas sociais e informada pela história, afasta Os parceiros do Rio Bonito dos estudos de comunidade, rejeitados por Antonio Candido "pelo que tem de estático e convencional" (Candido, 1971, p. 20). O autor localiza a pesquisa no universo das culturas "rústicas"; enquanto "rural" diz respeito à localização, "rústico" "pretende exprimir um tipo social e cultural, indicando o que é, no Brasil, o universo das culturas tradicionais do campo; as que resultaram do ajustamento do colonizador português ao Novo Mundo, seja por transferência e modificação dos traços da cultura original, seja em virtude do contato com o aborígene" (Candido, 1971, p. 21). 
Embora ligada à cultura que se desenvolveu nos latifúndios, a cultura rústica estaria mais próxima das culturas indígenas, e teria se desenvolvido de forma mais isolada, o que não implica isolamento total. ${ }^{\circ}$ O camponês pobre, mais ou menos presente de acordo com a região, seria o "representante típico". O caipira é o homem rústico da área delimitada pela colonização paulista. Ao estudar o caipira, a partir de sua formação histórica, Antonio Candido chama a atenção do leitor para os grupos marginalizados da colonização, ${ }^{10}$ não contemplados pelas interpretações mais amplas de nossa formação histórica até então. A exceção seria Euclides da Cunha, como afirma na palestra proferida em 1954: "Nous lui devons le premier effort pour caractériser la réalité propre aux cultures rustiques du Brésil, dont la genèse lui semblait être dirigée par l'isolement géographique et le mélange racial" (Candido, 1955, p. 323).

A relação entre a obtenção dos meios de vida e as formas de sociabilidade correspondentes constitui o tema central do estudo. Há aqui um "encontro" da teoria da história de Marx - o grupo é estudado a partir das relações que estabelece com a natureza para obter sua sobrevivência com o funcionalismo de Malinovski, que "mostraria que a satisfação das necessidades, sendo uma das molas da cultura, já se situa em pleno terreno institucional" (Candido, 1971, p. 25). Como se trata do estudo de grupo originado do colonizador português, em situação de mudança, Antonio Candido propõe um estudo comparativo entre o grupo estudado e a sociedade abrangente, recorrendo às noções de "mínimo vital" e "mínimo social". Os "mínimos" definem os limites para a sobrevivência física e social do grupo; abaixo deles estariam a fome e a anomia.

Da relação entre produção dos meios de vida e sociabilidade, destaca-se a produção da dieta, porque a alimentação seria a principal necessidade humana, inadiável em qualquer grupo e circunstância. A sociologia proposta pelo autor é chamada, então, de "sociologia dos meios de subsistência", buscando interpretar todas as dimensões da vida social, a partir da alimentação.

$\mathrm{Na}$ primeira parte do livro, é feita a reconstrução histórica a partir de documentos escritos, principalmente relatos de viajantes, e depoimentos de velhos caipiras, para alcançar o "tempo dos antigos". A conclusão é que a sociedade caipira se formara durante a expansão paulista, principalmente em seus momentos derradeiros (século XVIII), à medida que os homens abandonavam as expedições e fixavam moradia no interior paulista; suas características são, portanto, influenciadas por esse processo. Terra abundante, mobilidade constante, caráter aventureiro do mameluco e relação quase visceral com a natureza determinariam as formas de adaptação do caipira ao meio ambiente.

Do povoamento disperso resulta ainda a forma típica de organização social, o bairro, unidade mínima da sociabilidade caipira, "consistindo no agrupamento de algumas ou muitas famílias, mais ou menos vinculadas pelo sentimento de localidade, pela convivência, pelas práticas de auxílio mútuo e pelas atividades mágico-religiosas" (Candido, 1971, p. 62). O bairro situa-se entre os centros de povoamento urbano, aos quais recorre o caipira eventualmente, e o isolamento. A ocupação do território é, em geral, transitória, não constitui propriedade.

O trabalho familiar, base da economia, é complementado pela ajuda dos vizinhos, em atividades de que a família não dá conta; conforme a definição acima, "é membro do bairro quem convoca e é convocado" a participar do mutirão. Apesar de o aspecto econômico envolvido no mutirão ser importante para sua explicação, ele não o esgota. Aqui, a interpretação recorre a Lévi-Strauss: sua ocorrência está vinculada a um sistema de trocas que estabelece vínculos sociais entre os integrantes do bairro; do qual também fazem parte as trocas alimentares e as atividades mágico-religiosas. A vida social do caipira corresponde, entretanto, a um mínimo, uma vez que na maior parte do tempo prevalece o círculo familiar como cerne da sociabilidade. Trata-se de cultura que se transforma muito pouco no decorrer do tempo, e que recorre à tradição como recurso de ajustamento à nova situação, como veremos.

Na segunda parte do livro, a descrição da rotina dos parceiros é minuciosa. São descritas as técnicas de plantio para as diversas espécies de 
milho, arroz e feijão utilizadas. O tempo do parceiro é regulado pelo ritmo de seu trabalho na lavoura; assim, as unidades de tempo que importam são o dia, a semana e o ano agrícola. O mês, fundamental para o trabalhador assalariado, para ele pouco importa. As festas demarcam o ano: São Roque é o início, em agosto, e São João o fim, em junho. O trabalho é fundamentado na família, onde ocorre a divisão sexual do trabalho, e complementado pelo auxílio vicinal. Mas as modalidades de auxílio são diferentes das descritas para a cultura caipira tradicional, aparecendo mais as trocas de serviço do que o mutirão, que fica restrito à família e aos mais íntimos.

No grupo estudado, prevalecia em grande parte o cardápio tradicional: feijão, arroz e milho. O feijão é o "chefe da mesa". As misturas são raras; eventualmente frango, caça, ovos; quase nunca carne de vaca e pão. Pouco freqüentes no prato, as misturas não saiam da cabeça do caipira. Antonio Candido introduz aqui a "fome psíquica", frustração que acompanha o caipira, mesmo quando a fome física está satisfeita. Descreve, também, a obtenção dos ingredientes, o modo de preparar e temperar os alimentos, e as diversas situações em que ocorrem as refeições. As oportunidades de comer algo diferente surgiam nas festas, religiosas ou não, e quando algum vizinho matava um animal, em geral porco, e oferecia carne. Ao contrário do que diziam folcloristas como Cornélio Pires, a dieta caipira era, portanto, pobre e mal equilibrada. A segunda parte do livro descreve, enfim, a etnografia centrada na dieta do parceiro de Bofete, mas os dados recolhidos servem, também, como fonte para reconstituir a vida caipira tradicional e para o estudo sobre a família caipira, publicado em anexo no livro.

A terceira parte, "Análise da Mudança", interpreta sociologicamente os dados recolhidos na etnografia. Se a primeira parte nos remete para os clássicos dos anos 30 e 40, esta deve ser lida a partir das preocupações teóricas que orientam grande parte dos trabalhos publicados nos anos 40 e 50 . Na antropologia, com o impacto dos "estudos de comunidade", introduzidos no Brasil por Emílio Willems e Donald Pierson, respectivamente na USP e na Escola Livre de Sociologia e Polí- tica, a questão fundamental é entender a natureza da mudança social nas comunidades. Na sociologia, a partir dos anos 50, as pesquisas se voltam para a explicação das grandes transformações que ocorrem na sociedade brasileira naquele momento, relacionadas à modernização do país, em função da aceleração dos processos de industrialização, urbanização, formação da sociedade de classes e democratização política.

A interpretação de Antonio Candido integra essas duas questões a partir da análise da situação de crise da cultura caipira, em face da expansão da economia capitalista. No grupo de parceiros estudado, o autor busca diferenciar os fatos que indicam persistência de padrões tradicionais dos que apontam a alteração. Como o momento é de crise, os segundos prevalecem em relação aos primeiros.

Em face da crescente imposição de necessidades pelo mercado capitalista, o caipira vai aos poucos integrando sua vida econômica à economia geral. Sistema tradicionalmente semi-fechado, a crise da cultura caipira se expressa, então, nos problemas decorrentes de sua integração ao capitalismo. O caipira dependia antes da mobilidade e de terra abundante para amenizar os prejuízos decorrentes da adaptação precária ao meio ambiente; na nova situação, sua sobrevivência torna-se cada vez mais difícil. Diante do mercado, ele é obrigado a intensificar o ritmo de trabalho para conseguir complementar sua produção; a regularidade dos preços, na compra dos produtos de que necessita, não é acompanhada pela regularidade na venda do que produz. Esse problema, acrescido da dificuldade de racionalizar a economia doméstica, conduz ao desequilíbrio. Alguns conseguem se adaptar ao novo modo de vida, outros acabam na miséria.

Na nova forma de ajuste social, o mundo do caipira fragmenta-se: as várias dimensões ganham autonomia neste processo; não há mais interpenetração de trabalho, lazer e religiosidade. Embora não faça referência direta a Weber ou Marx, Antonio Candido mostra que a transformação da cultura caipira está submetida à racionalização crescente descrita por Weber e à alienação provocada pela mercadoria no capitalismo, conforme Marx. 
Também as posições sociais se alteram: da indiferenciação tradicional, passamos a uma estrutura social que se reorganiza no sentido da sociedade de classes. Todas as transformações descritas geram desequilíbrio na sociedade caipira, e a sobrevivência do grupo fica seriamente ameaçada. Como reage o caipira a esse processo?

De maneira geral, a cultura caipira caminha para o fim inevitável, mas revela ao mesmo tempo formas de resistência. A crise cultural provoca reações psicológicas complexas no caipira. Como vimos, as técnicas tradicionais são abandonadas e desprezadas, mas as dificuldades crescentes de adaptação ao universo capitalista tem como contraponto a valorização do passado.

Ninguém trabalhava alugado, porque para isto havia os cativos; não havia aforante nem colônio: era o "tempo das posse" e todos tinham a sua terra. Era só chegar, tomar conta e pedir para o Governo, que concedia áreas medindo uma légua de frente por três de fundo. Mas depois vieram os fazendeiros ricos e como a caboclada era ignorante, foram comprando barato de uns, tomando à força de outros (Candido, 1971, p. 194). ${ }^{11}$

A contraposição da dissolução da sociedade caipira e da resistência cultural acaba matizando o pessimismo da análise. A repulsa do parceiro ao trabalho assalariado, a mobilidade na medida ainda possível, a formação de blocos familiares onde são preservados os fatores de sociabilidade são interpretadas como resistência. Mas as formas de resistência não significam para o autor uma saída viável para a crise que enfrenta o caipira.

Se o processo de incorporação à vida urbana deixa o caipira em condição precária, muitas vezes de miséria, é porque não há vontade política de integrar o homem rústico, ou de contribuir para a melhoria de seu nível de vida. A conclusão de Antonio Candido é política: se o fator limitante para a sobrevivência física, em primeiro lugar, e social, em segundo, é a indisponibilidade de terra, a solução é a reforma agrária. Em nenhum momento do livro, embora haja simpatia pelo caipira, há a defesa do retorno à vida tradicional, que, como vimos, resultava de ajuste mínimo ao meio ambiente. De forma sintética, o que se propõe é a inclusão e não a exclusão das populações rústicas, inseridas em processo de urbanização inevitável. A proposta de Antonio Candido é limitada, entretanto, pela sua interpretação, que retira do caipira e do homem rústico qualquer possibilidade de ação política autônoma. ${ }^{12}$

Escrito na década de 50, quando a grande preocupação era buscar orientação cada vez mais científica na USP, Os parceiros do Rio Bonito afastou-se do "espírito" acadêmico vigente e causou certo estranhamento. Embora tenha sido bem recebido - o livro teve oito edições entre 1964 e 1998 - foi criticado, sobretudo nos anos 60, por misturar esquemas teóricos aparentemente incompatíveis e também por apresentar linguagem pouco científica.

A interpretação que se segue recorre à leitura de textos do autor, desde a tese sobre Sílvio Romero, nos quais verifica-se o esforço de descrever o processo de formação do pensamento brasileiro - Formação da literatura brasileira é o núcleo desta reflexão. Na produção especificamente sociológica, estão relacionadas com o tema: "Euclides da Cunha sociólogo", 1952; "Informação sobre a sociologia em São Paulo", artigo publicado originalmente em 1954; "L'état actuel et les problèmes les plus importants des études sur les sociétés rurales du Brésil", 1955; e "A sociologia no Brasil", 1957. Outros artigos importantes dentro desta orientação são: "O significado de Raizes do Brasil", publicado em 1963 como prefácio do livro de Sérgio Buarque; "Literatura e cultura de 1900 a 1945", publicado em 1965 no livro Literatura e sociedade; "Literatura e subdesenvolvimento", 1970; "A Revolução de Trinta e a cultura", 1983; "Radicalismos", 1990.

Podemos tomar suas reflexões sobre a formação do pensamento brasileiro para entender aspectos de sua obra; isso porque, ao mesmo tempo em que interpreta os autores de nossa literatura e de nosso pensamento social, com a preocupação de esclarecer o processo de formação do pensamento brasileiro, Antonio Candido fixa sua posição teórica, embora quase sempre o faça de maneira muito sutil. Nesse sentido, o que diz de outros autores pode servir de referência para compreendermos sua obra. 
Em Formação da literatura brasileira, além de estudar esteticamente as obras, Antonio Candido descreve a formação do "sistema literário" brasileiro. A importância do livro, para compreendermos a constituição da sociologia, entre outras especialidades do pensamento brasileiro no século XX, é que a literatura seria, até as décadas de 20 e 30, a forma preferencial de reflexão sobre o Brasil. Em nossa literatura, a configuração do "sistema literário" ocorre durante o arcadismo e o romantismo, aproximados pela mesma "vocação histórica", traduzida pela consciência por parte dos escritores de seu papel na constituição da literatura nacional. No romantismo, o nacionalismo intensifica-se em função do processo de independência e de construção do Estado Nacional. Antes da passagem para o romantismo, entretanto, na fase decadente do arcadismo, surgem os gêneros públicos que, em função da efervescência política e da rotinização literária, prevalecem diante da produção literária e marcam o pequeno "surto das luzes" brasileiro. A forma mais expressiva é o jornalismo de ensaio, e o nome mais importante, Hipólito da Costa. Este período é rapidamente superado com a emergência do romantismo, mas sua importância é grande porque revela, pela primeira vez em forma não literária, uma reflexão crítica sobre a realidade brasileira. Nesse momento, conforme Antonio Candido, define-se por aqui o papel do intelectual que se integra na vida social e política e liberta-se da religião. A grande preocupação é questionar a relação metrópole-colônia e, depois da independência, indagar sobre o progresso do país, para interferir diretamente nesse processo, indicando os rumos a serem tomados.

Efetivada a passagem do arcadismo ao romantismo pelo "grupo da Niterói", liderado por Gonçalves de Magalhães, a reflexão sobre nossa realidade volta à forma literária. O nacionalismo é anterior à reforma romântica, mas, absorvido por ela, constitui-se em um de seus principais aspectos. Manifesta-se na preocupação quase unânime dos escritores de descreverem a natureza, os costumes, a história e os sentimentos brasileiros. Tal seria a estratégia para tornar nossa produção literária independente. $\mathrm{O}$ indianismo desponta aqui como tema central, simbolizando o "nacionalismo literário". O índio é idealizado pelos poetas românticos, que atribuem a ele a origem de nossa história. Mais comprometido com a realidade, o romance torna-se o veículo adequado para expressar a ideologia nacionalista. Inicialmente pobre, vai sendo sofisticado até Machado de Assis, onde se revela a maturidade da literatura brasileira. O processo de amadurecimento é, para Antonio Candido, resultado do longo processo de formação. A emergência de Machado não é explicada a partir das influências externas, ainda que sejam também importantes, mas das internas:

$\mathrm{Na}$ verdade, ele [Machado] foi, sob vários aspectos, continuador genial, não figura isolada e literariamente sem genealogia no Brasil, tendo encontrado em Alencar, além da sociologia da vida urbana, sugestões psicológicas muito acentuadas no sentido da pesquisa profunda (Candido, 1993 , vol. 2, p. 193).

Depois de percorrer a produção literária no arcadismo e no romantismo, Formação da literatura brasileira termina com um estudo sobre a gênese da crítica literária no Brasil. Como no capítulo em que nos informa as condições históricas e literárias que permitiram o surgimento dos gêneros públicos, importa-nos a relação direta com o tema central da obra - a formação do sistema literário - mas também perceber que o surgimento da crítica é parte do processo de diferenciação do trabalho artístico e intelectual; em outros termos, de nossa formação cultural erudita.

Antonio Candido fecha o livro citando Machado de Assis. A citação vem do artigo "Instinto de nacionalidade"; a idéia defendida por Machado é simples e decisiva: uma literatura nascente não pode restringir-se a temas locais, uma vez que a independência só é alcançada quando os autores têm competência para tratar de temas universais. Retomando a tese central de Formação da literatura brasileira, a formação do sistema literário se completa no romantismo. Ao final do século XIX, o sistema está maduro, o que se comprova pela obra de Machado de Assis. Nele, a combinação entre as influências que absorve de nossos escritores se combinam com as influências externas, para produzir uma obra universal. O horizonte de nos- 
so autor não é, portanto, a separação de nossa literatura das que a originaram, mas sua reintegração. Nos termos de Roberto Schwarz, Antonio Candido não é nacionalista, mas "internacionalista”. Em Formação da literatura brasileira, Antonio Candido reconstrói a formação de nossa literatura como sistema e sugere que nela está a origem de nossa vida intelectual e artística; a crítica literária e o pensamento social aparecem inicialmente como gêneros literários e se autonomizam progressivamente. Vejamos o depoimento do autor:

Formação da literatura brasileira é de certa maneira um estudo de formação do pensamento brasileiro no campo da literatura. Lá, eu digo que não pretendi fazer uma mera história da literatura, dos textos literários. É um estudo sobre a vontade dos brasileiros de terem uma literatura. "Como é que os brasileiros pensaram a literatura?" Este é o ângulo do meu livro, ou seja, como é que os brasileiros foram concebendo aos poucos a literatura, como é que eles foram se sentindo mais originais. Nela, me ponho no ponto de vista histórico. Acredito na causação histórica, embora ela não possa ser determinada com precisão. Não há causação histórica de tipo mecânico, é claro, pois os fatos históricos se produzem em função de uma quantidade de fatores, que derivam uns dos outros. Procurei observar isto na literatura. É de certa maneira um capítulo da formação do pensamento brasileiro no terreno da literatura, não só a produção dos textos literários, mas como, ao lado da criação dos textos literários, os brasileiros pensavam no significado histórico dessa elaboração. Pensando nisto, eles pensavam o seu país (depoimento concedido em 30/09/1996).

A obra termina no final do século XIX, ponto de partida de "A sociologia no Brasil" e também de "L'état actuel et les problèmes les plus importants des études sur les sociétés rurales du Brésil". Antonio Candido divide o processo de formação da sociologia no Brasil em três fases: a primeira, 1880-1930, marcada por estudos não especializados e voltados para interpretações globais do Brasil; a segunda, transitória, 1930-1940, é o momento de publicação dos ensaios histórico-sociológicos de Gilberto Freyre, Sérgio Buarque e Caio Prado Jr.; a terceira, 1940 em diante, é a fase de "consolidação e generalização da sociologia como dis- ciplina universitária" e da "produção regular no campo da teoria, da pesquisa e da aplicação" (Candido, 1957, p. 2107). No final do século XIX, a influência do evolucionismo é determinante e os intelectuais, em sua maioria juristas, formulam, a partir dos fatores naturais, principalmente a raça, as etapas de nossa evolução histórica. A "superação" do evolucionismo ocorreria através de Euclides da Cunha, que e Os sertões apresentava "uma fórmula bem brasileira de estudos sociais, em que a reconstrução do passado se amoldava a certos pontos de vista do presente; em que o estudo se misturava à intuição pessoal e o cientista ao retórico, ou ao escritor"(Candido, 1957, p. 2107). Euclides é um autor chave no esquema de Antonio Candido. Sua importância se explica pela originalidade da análise em Os sertões, voltada para a parte da sociedade brasileira esquecida pelas análises precedentes, e também pelas posteriores, que interpretaram o Brasil a partir das classes dominantes e/ou das relações sociais e políticas centralizadas no latifúndio. Na literatura, rompeu com a visão idealizada do homem rural brasileiro, que seria ainda por certo tempo a tônica de estudos folcloristas feitos por escritores como Valdomiro Silveira, Amadeu Amaral e outros. Como Ś́lvio Romero, Euclides baseou-se no determinismo geográfico e racial, mas as conclusões mais importantes do livro teriam sido retiradas do fato presenciado pelo autor em Canudos, onde esteve, como se sabe, como repórter de O Estado de S. Paulo. Este é mais um aspecto destacado, sua interpretação é retirada do contato direto com a realidade:

Do acontecimento, Euclides extrai limpidamente a teoria, salientando o significado social da coexistência de dois Brasis, cujas relações poderiam tomar, periodicamente, um sentido de grande tragédia coletiva, se não se desenvolvesse uma política adequada para superar a distância entre ambos (Candido, 1957, p. 2110).

A preocupação com Euclides, no que diz respeito à sociologia, já havia sido revelada dez anos antes - 1947 - em conferência proferida em São José do Rio Pardo, na semana euclideana. Com poucas alterações o texto seria publicado em OESP, 1952, em página comemorativa dos cin- 
qüenta anos de Os sertões. Os títulos indicam, talvez, pequena diferença. O texto inédito de 1947 é "O sociólogo em Euclides da Cunha"; o de 1952 é "Euclides da Cunha sociólogo". Se os argumentos não se alteram substancialmente, confirmando que há em Os sertões uma reflexão sociológica, embora informada pelas teorias deterministas do século XIX, os títulos indicam conclusões ligeiramente distintas. Enquanto o primeiro chama a atenção para o "sociólogo" escondido nas entrelinhas do livro, o segundo afirma Euclides como sociólogo. Se esta inferência é correta, indica uma questão de fundo que norteia a produção sociológica de Antonio Candido acerca do estatuto epistemológico da disciplina.

Mas com isso tudo, e talvez por causa disso tudo, a sua interpretação tem um toque de gênio, porque, mais, muito mais que um sociólogo, foi uma espécie de iluminado. As simplificações que operou, na síntese das grandes visões de conjunto, lhe permitiram captar a realidade mais profunda do homem brasileiro do sertão (Candido, 1947, p. 7).

A diferença sutil de um texto para outro repousa no impacto deste parâmetro - a capacidade de captar profundamente a realidade social para definir uma abordagem sociológica. De "O sociólogo em Euclides da Cunha" para o "Euclides da Cunha sociólogo" amadurece a concepção de sociologia menos formal e científica e mais intuitiva e literária. ${ }^{13}$

Euclides é, portanto, ao lado de Gilberto Freyre, o representante mais típico da "forma bem brasileira de investigação e descoberta do Brasil", que se situa entre literatura e ciência. A investigação pouco sistemática é compensada pela intuição e qualidade literária do escritor, oriundo, como vimos, de tradição literária comprometida com a descrição e análise da realidade brasileira. É importante também a preocupação política de Euclides com o destino das populações rurais brasileiras, ou, nos termos de Antonio Candido, com os grupos rústicos, que englobam tanto os "fanáticos" de Antonio Conselheiro, como os caipiras de Os parceiros do Rio Bonito.

O terceiro autor destacado na exposição é Oliveira Vianna. Ao contrário de Euclides da Cu- nha, Oliveira Vianna defendia estudos mais amplos, não monográficos, voltados para a compreensão da evolução social brasileira. Tal atitude se explicaria, segundo Antonio Candido, pelo nacionalismo vigente. O esquema do autor deságua em proposta política e administrativa, retirada de sua análise da sociedade centrada na família, que seria o núcleo da sociedade brasileira. A solução preconizada é a centralização política e a racionalização administrativa. Na formação da sociologia, o autor aparece como "o divisor de águas entre a tendência para a vista sintética, como dizia Sílvio Romero, e a necessidade de discriminar tipos sociais, de que Euclides fora o precursor" (Candido, 1957, p. 2113).

Até a época de Oliveira Vianna, apesar da carência de teoria e de "métodos diretos de pesquisa empírica da realidade presente", já havia "consciência dos fatos essenciais da realidade brasileira que lhe competia estudar"; "pontos de vista coerentes sobre o país"; e "critérios explicativos", "como o recurso à história, o estudo da adaptação ao meio, a avaliação das etnias na formação social, o senso da complexidade cultural" (Candido, 1957, p. 2113). Na fase de transição, nos anos 30, a renovação teórica e metodológica de Gilberto Freyre seria a ponte entre os precursores da sociologia e a sociologia como disciplina científica consolidada. A renovação de Gilberto Freyre está, todavia, ligada a processo histórico mais amplo: as transformações sociais e políticas decorrentes da crise da República Velha e da Revolução de Trinta. Esta seria o "eixo" das transformações que atingem também a cultura, "sacudida" na década de 20 pelo modernismo. No ensaio "Literatura e cultura de 1900 a 1945", publicado em 1953 na Alemanha e em 1965 no livro Literatura e sociedade, Antonio Candido destaca o romantismo e o modernismo como "momentos decisivos" da literatura brasileira. No plano temático, o modernismo seria o momento da superação do nacionalismo pitoresco, marcado pela idealização, propondo o estudo do homem brasileiro, conforme os trechos seguintes:

Na nossa cultura há uma ambigüidade fundamental: a de sermos um povo latino, de herança cultural européia, mas etnicamente mestiço, si- 
tuado no trópico, influenciado por culturas primitivas, ameríndias e africanas. Esta ambigüidade deu sempre às afirmações particularistas um tom de constrangimento, que geralmente se resolvia pela idealização [...]. O modernismo rompe com este estado de coisas [...]. O mulato e o negro são definitivamente incorporados como temas de estudo, inspiração, exemplo. O primitivismo é agora fonte de beleza e não mais empecilho à elaboração da cultura. Isso, na literatura, na pintura, na música, nas ciências do homem (Candido, 1976, p. 119)

Na década de 30, as inovações modernistas são incorporadas pela cultura brasileira, e Gilberto Freyre é um de seus representantes, ao lado de Sérgio Buarque, através do ensaio histórico-sociológico. A preocupação de estudar a realidade brasileira manifesta-se no grande número de estudos publicados, principalmente nas coleções "Brasiliana" e "Documentos Brasileiros" (conforme "A Revolução de Trinta e a cultura"). Tanto em "A sociologia no Brasil", como em "Literatura e cultura de 1900 a 1945", Antonio Candido destaca, como forma típica de expressão do nosso pensamento, esta espécie de sincretismo entre literatura e sociologia:

Não será exagerado dizer que esta linha de ensaio - em que se combinam com felicidade maior ou menor a imaginação e a observação, a ciência e a arte, - constitui o traço mais característico e original do nosso pensamento. Notemos que, esboçado no século XIX, ela se desenvolve no atual, onde funciona como elemento de ligação entre a pesquisa puramente científica e a criação literária, dando graças a seu caráter sincrético, uma certa unidade ao panorama de nossa cultura (Candido, 1976, p. 130).

Outro fato marca radicalmente a década de 30: são as reformas educacionais que têm como um de seus aspectos a fundação da USP, em 1934, e a criação dos cursos de Filosofia, Letras e Ciências Sociais. Somente com a emergência do ensino e da pesquisa academicamente conduzida, a sociologia sairia do "amadorismo". Nos termos de Antonio Candido, na USP ocorreria a passagem do "ponto de vista sociológico" para a "ciência da sociologia”. Nesse processo é fundamental a participação dos professores estrangeiros, responsáveis pela difusão de teorias e métodos de pesquisa e também de um novo "espírito", mais científico e profissional, e menos literário. Nas décadas de 40 e 50, o ensino e a pesquisa, marcados pela nova orientação trazida pelos professores estrangeiros, consolidam a sociologia como disciplina científica diferenciada.

$\mathrm{Na}$ última parte de "A sociologia no Brasil", Antonio Candido descreve as tendências da nova disciplina e revela sua posição, embora o faça discretamente. De acordo com o "espírito" vigente na década de 50, são reforçados os aspectos considerados científicos - teorias, métodos, técnicas, pesquisa empírica - enquanto os aspectos estéticos são menosprezados. O processo indica maturidade científica, e também esforço para romper com a tradição do pensamento brasileiro, marcado pelo sincretismo, "sincretismo que pode parecer indevido e talvez o seja em certa medida, mas corresponde a características da nossa evolução mental e necessidades ainda sentidas de compreensão da nossa realidade". A indiferenciação intelectual, sinal de amadorismo, teria como contrapartida a vantagem de permitir ao "espírito e aos métodos sociológicos estenderem-se por vários setores que lhe estariam vedados em países de especialização acadêmica mais estrita, enriquecendo o conhecimento da realidade e facultando maior plenitude à personalidade dos estudiosos" (Candido, 1957, p. 2118).

A mensagem de Antonio Candido parece clara: embora a especialização acadêmica seja requisito para a consolidação da sociologia como disciplina científica, o rigorismo metodológico e teórico pode limitar a sensibilidade do pesquisador para compreender a realidade. Retomando o texto "L'état actuel et les problèmes les plus importants des études sur les sociétés rurales du Brésil", 1955, e o prefácio de Os parceiros do Rio Bonito, a crítica aos estudos de comunidade principalmente Cunha, de Willems, e Cruz das Almas, de Pierson - reside justamente na falta de sensibilidade para perceber os problemas mais amplos ligados às sociedades rústicas. A diferença mais importante, neste sentido, é que Antonio Candido recorre à história para compreender o grupo estudado. Como sugeri neste capítulo, isso se deve à sua orientação marxista, mas também à 
influência que recebeu dos ensaios histórico-sociológicos da década de 30 .

A aproximação de Os parceiros do Rio Bonito com a geração de trinta deve ser, evidentemente, matizada. O tema escolhido, a pesquisa empírica realizada, assim como a sustentação teórica do trabalho se devem, em grande parte, à formação científica recebida na USP. As leituras antropológicas, por exemplo, foram introduzidas por Emílio Willems, nos seminários que organizou para os alunos de doutorado, no início da década de 40. Roger Bastide influenciou não só a escolha do tema, mas também a atitude do pesquisador, valorizando suas interpretações individuais. Qualquer exemplo será insuficiente, entretanto, para mostrar a importância da formação acadêmica de Antonio Candido em sua obra. De qualquer forma, parece-me fundamental em Os parceiros do Rio Bonito a recuperação do ensaísmo, através de um estudo aparentemente restrito, mas que sugere nas entrelinhas uma interpretação abrangente de nossa formação social. Se esta leitura é possível, então seu grande precursor é Os sertões, que interpretou o Brasil a partir de Canudos, além de Casa-grande \& senzala, Raizes do Brasil e Formação do Brasil contemporâneo.

Antonio Candido faz em Os parceiros do Rio Bonito mais do que uma monografia sobre o caipira. Partindo da cultura caipira, incorpora os clássicos brasileiros e sugere que o conhecimento e a transformação do Brasil real dependem não apenas dos grandes esquemas, mas também de interpretações voltadas para os grupos excluídos, com os quais se encontra na figura do antropólogo. O livro mostra que a transformação do Brasil rural agrava o processo de exclusão social, pois ignora os verdadeiros produtores de sua história, e que esse processo só poderia ser superado pela reforma agrária, pautada por estudos voltados para a cultura.

Distanciado dos ensaios histórico-sociais dos anos 30 e 40 pela tradição teórica e metodológica aqui fixada pelos professores franceses e americanos, Os parceiros do Rio Bonito, não obstante, se aproxima pela preocupação geral de compreender o processo de formação da sociedade brasileira, indicar os problemas que o emperram e pro- por mudanças para superá-los. Temos aqui, portanto, a forma de Raizes do Brasil ou de Formação do Brasil contemporâneo. A preocupação de escrever literariamente, sem abusar de jargões, também recupera a tradição. Como sugere Paulo Arantes a respeito de Formação da literatura brasileira, as influências mais determinantes não vêm de fora; elas são recolhidas na tradição brasileira e elaboradas teoricamente, na medida em que o objeto de pesquisa, neste caso o universo das culturas rústicas, assim o exige. A distância temática que separa Formação da literatura brasileira e Os parceiros do Rio Bonito deve ser, portanto, relativizada. Embora sejam livros muito distintos, aproximam-se pela preocupação de compreender o processo histórico e os fundamentos da nação brasileira, apesar de tratarem de dimensões diferentes da realidade e da história. A "tradição esquecida" da cultura caipira e dos parceiros recupera, assim, na escritura de Antonio Candido, a longa tradição de nosso pensamento, em relação ao qual o saber acadêmico da USP procurava se diferenciar nos anos 50 e 60 .

\section{NOTAS}

1 Analisamos a trajetória do autor em nossa dissertação de mestrado (defendida em outubro de 1998, no Departamento de Sociologia da FFLCH/USP), a ser publicada ainda este ano pela Editora UFMG. Este texto é uma versão resumida e mutilada, que privilegia a interpretação de Os parceiros do Rio Bonito. Sobre a história das ciências sociais em São Paulo, há bibliografia recente, da qual destaca-se História das Ciências Sociais no Brasil (vols. 1 e 2), publicação organizada por Sergio Miceli, a partir de projeto realizado no Idesp.

2 "Estímulos da criação literária" - incluído em Literatura e sociedade - expressa a relação íntima entre crítica literária e sociologia na obra do autor. O livro é fundamental na obra do autor e seu título muito sugestivo: indica os temas principais de Antonio Candido e, além disso, a pretensão de os aproximar analiticamente. "Estímulos da criação literária" segue diretamente esse passo, e de forma muito concreta. Isso porque o texto, embora reformulado em Literatura e sociedade, fazia parte da tese sobre o cururu, abandonada pelo autor, mas que dera origem a Os parceiros do Rio Bonito. De grande interesse para a sociologia da arte e da literatura, o tex- 
to compara as possibilidades de análise das manifestações artísticas "eruditas" às possibilidades de análise das mesmas em sociedades "primitivas" e "rústicas". Genericamente, sugere que o vínculo entre arte e estrutura social é mais intenso nestas, o que torna a perspectiva sociológica indispensável no estudo da "cultura popular", associada à análise formal. No estudo de formas eruditas, a sociologia da cultura assumiria o papel de disciplina auxiliar dada a possibilidade de restringir a análise exclusivamente a aspectos formais em função da autonomização da arte em relação à estrutura social.

3 Entre 1942 e 1958, enquanto esteve vinculado à cadeira de Sociologia II, regida por Fernando de Azevedo, o autor publicou doze artigos de sociologia Os parceiros do Rio Bonito foi publicado em 1964. Como crítico, nos anos 40 e 50, publicou 5 livros: Introdução ao método crítico de Sílvio Romero, 1945; Brigada ligeira, 1945, Ficção e confissão, 1956; Formação da literatura brasileira, 1959; O observador literário, 1959; e mais de duzentos artigos de crítica (incluindo estudos, ensaios, artigos e notas) em jornais, revistas e coletâneas.

4 Os parceiros do Rio Bonito foi elaborado entre 1948 e 1954 e Formação da literatura brasileira entre 1946 e 1957.

5 Um dos principais historiadores da República Brasileira, professor aposentado do Departamento de História da FFLCH/USP, escreveu obra extensa, iniciada pelo pequeno mas clássico Revoluções do Brasil contemporâneo (1922-1938). Sobre a fazenda Bela Aliança, Edgard Carone escreveu um livro de memórias, Memória da fazenda Bela Aliança, no qual relata, além de sua experiência pessoal, a história da fazenda adquirida por seu pai por volta de 1930.

6 Regime de trabalho no qual o trabalhador dá parte da produção ao proprietário da terra em troca de lote para plantar. Em Os parceiros do Rio Bonito, várias modalidades são descritas no capítulo 7, "População rural e parceria", da segunda parte do livro.

7 Fernando Henrique Cardoso estrutura a argumentação de Antonio Candido em três níveis, diferenciando as preocupações concretas e teóricas do livro: "O estudo, ao estilo das 'análises de comunidade' da boa inspiração antropológica, dos meios de vida do caipira paulista; a caracterização mais geral da cultura do caipira; e a preocupação teórica com a importância dos 'mínimos de sociabilidade"" (Cardoso, 1979, p. 90).

8 Maria Sylvia de Carvalho Franco publicou em 1992 um pequeno ensaio, "Prosa com Os parceiros do Rio Bonito", enfatizando as soluções metodológicas da obra, assim como seu alcance teórico e substantivo.
A decisão de combinar o antropólogo com o sociólogo, que permite "reconstituir a 'vida caipira tradicional', ao mesmo tempo individualizada e submetida aos processos universais da cultura", o recurso à história oral, que recupera "detalhes significativos"e a recusa da "generalidade abstrata do sociólogo" e do "corte descritivo dos 'estudos de comunidade" permitiria, segundo a autora, particularizar e generalizar ao mesmo tempo.

9 O isolamento era para Euclides da Cunha a característica determinante da sociedade sertaneja; Antonio Candido reforça que o isolamento é parcial, porque sempre há alguma forma de contato com a sociedade abrangente, mesmo que limitada e esporádica.

10 Em "A sociologia no Brasil", o autor revela dado de grande importância: os grupos rústicos constituíam na década de 50 a maior parte da população brasileira. Nesse sentido, estudos que esclareçam a história e as formas de organização social e cultural são fundamentais para a compreensão e problematização do Brasil como um todo.

11 A passagem revela a preocupação literária em Os parceiros do Rio Bonito. Para descrever a valorização do passado pelo caipira, o autor desloca o foco narrativo e quem interpreta essa reação psicológica é um parceiro imaginário.

12 Devemos estar atentos ao momento da redação da tese, que termina em 1954. O movimento das ligas camponesas ocorre em 1955, e atrai a atenção dos diversos grupos políticos para o que está ocorrendo no campo. Depois disso, a reforma agrária passa a ser discutida nacionalmente. Devo ao professor José de Sousa Martins essa advertência.

13 A afirmação deve ser matizada, não se trata de recusar os métodos e as teorias da sociologia, mas de relativizá-los, principalmente quando se avalia o mérito de um autor. Deve-se levar em conta o contexto intelectual no qual ele esteve inserido. Nesta perspectiva, as limitações de métodos e teorias aparecem como inerentes a todas as épocas e a interpretação deve procurar parâmetros mais gerais, para poder comparar autores separados pelo tempo e pelas escolas. A posição de Antonio Candido aproxima-se da defendida por Redfield no texto "The art of social science". 


\section{BIBLIOGRAFIA}

Entrevistas concedidas ao pesquisador

CANDIDO, Antonio, 6 de junho de 1996 e 30 de setembro de 1996.

CARONE, Edgard, 6 de julho de 1996.

PRADO, Décio de Almeida, 12 de março de 1997.

MARTINS, José de Souza, 26 de junho de 1997.

Artigos e livros de Antonio Candido

(1947), "O sociólogo em Euclides da Cunha”, inédito.

(1949), "Sociologia, ensino e estudo". Sociologia, São Paulo, 11 (3).

(1951), "Brazilian family", in SMITH, T. Lynn e MARCHANT, Alexander (orgs.), Brazil. Portrait of half a continent, Nova York, The Dryden Press.

. (1952), "Euclides da Cunha sociólogo". O Estado de S. Paulo, São Paulo, 13 de dezembro.

(1954), "A vida familial do caipira". Sociologia, São Paulo, XVI (4).

(1954), "A sociologia em São Paulo". O Estado de S. Paulo, São Paulo, 25 de janeiro.

(1955), "L'état actuel et les problèmes les plus importants des études sur les sociétés rurales du Brésil". Anais do 31. Congresso Internacional de Americanistas. São Paulo.

. (1956), "Possíveis raízes indígenas de uma dança popular". Revista de Antropologia, São Paulo, 4 (1).

(1957), "A sociologia no Brasil", in Enciclopédia Delta Larousse, São Paulo, vol. IV.

(1968 [publicado originalmente em 1966]), "O significado de Raizes do Brasil", in HOLANDA, Sérgio Buarque de, Raizes do Brasil, Rio de Janeiro, José Olympio.
(1971), Os parceiros do Rio Bonito. São Paulo, Duas Cidades.

(1976), Literatura e sociedade. São Paulo, Companhia Editora Nacional.

(1976), "Literatura e cultura de 1900 a 1945", in Literatura e sociedade, São Paulo, Companhia Editora Nacional.

(1989), A educação pela noite e outros ensaios. São Paulo, Ática.

(1989), "Literatura e subdesenvolvimento", in A educação pela noite e outros ensaios, São Paulo, Ática.

(1989), "A Revolução de 30 e a cultura", in A educação pela noite e outros ensaios, São Paulo, Ática.

(1993), Formação da literatura brasileira. São Paulo, Martins, 2 vols.

(1995), Vários escritos. São Paulo, Duas Cidades.

(1995), "Radicalismos", in Vários escritos. São Paulo, Duas Cidades.

(1996), Recortes. São Paulo, Companhia das Letras.

Livros e artigos de outros autores

ARANTES, Paulo E. (1992), "Providências de um crítico literário na periferia do capitalismo, in D'INCAO, Maria Angela e SCARABÔTOLO, Eloísa Faria (orgs.), Dentro do texto, dentro da vida, São Paulo, Companhia das Letras.

ARANTES, Paulo E. e ARANTES, Otília F. A. (1997), "Moda caipira", in _. Sentido da formação, Rio de Janeiro, Paz e Terra.

ARRUDA, Maria Arminda do Nascimento (1995), "A sociologia no Brasil: Florestan Fernandes e a 'escola paulista', in MICELI, Sergio (org.), História das Ciências Sociais no Brasil, São Paulo, Sumaré/Idesp/Fapesp, vol. 2.

BASTIDE, Roger (1983), "A propósito da poesia como método sociológico”, in QUEIROZ, 
Maria Isaura P. (org.), Roger Bastide: sociologia, São Paulo, Ática.

CARDOSO, Fernando Henrique (1979), "A fome e a crença”, in LAFER, Celso (org.), Esboço de figura - homenagem a Antonio Candido, São Paulo, Duas Cidades.

CARONE, Edgard (1991), Memória da fazenda Bela Aliança. Belo Horizonte, Oficina de Livros.

CUNHA, Euclides da (1993), Os sertões. São Paulo, Cultrix.

FERNANDES, Florestan (1992), "O mestre exemplar", in D'INCAO, Maria Angela e SCARABÔTOLO, Eloísa Faria (orgs.), Dentro do texto, dentro da vida, São Paulo, Companhia das Letras.

(1958), A etnologia e a sociologia no Brasil. São Paulo, Anhembi.

FRANCO, Maria Sylvia de Carvalho (1983), Homens livres na ordem escravocrata. São Paulo, Kairós.

(1992), "Prosa com Os parceiros do Rio Bonito", in D'INCAO, Maria Angela e SCARABÔTOLO, Eloísa Faria (orgs.), Dentro do texto, dentro da vida, São Paulo, Companhia das Letras.

FREYRE, Gilberto (1992), Casa-grande \& senzala. Rio de Janeiro, Record.

(1967), Nordeste. Rio de Janeiro, José Olympio.

HIRANO, Sedi (1992), "Tradição e mudança social no Brasil", in D'INCAO, Maria Angela e SCARABÔTOLO, Eloísa Faria (orgs.), Dentro do texto, dentro da vida, São Paulo, Companhia das Letras.

HOlANDA, Sérgio B. (1975), Raizes do Brasil. Rio de Janeiro, José Olympio.

. (1989), Monções. 3 ed. São Paulo, Brasiliense.

(1949), "Índios e mamelucos na expansão paulista". Anais do Museu Paulista, vol. XIII.

MARTINS, José de Souza (1993), "Os novos sujeitos das lutas sociais, dos direitos e da po- lítica no Brasil rural", in . A chegada do estranho, São Paulo, Hucitec.

MICELI, Sergio (org.) (1989), História das Ciências Sociais no Brasil. São Paulo, Vértice/Idesp/Finep, vol. 1.

(org.) (1995), História das Ciências Sociais no Brasil. São Paulo, Sumaré/Idesp/Fapesp, vol. 2.

PONTES, Heloisa (1998), Destinos mistos: os críticos do grupo Clima em São Paulo (19401968). São Paulo, Companhia das Letras.

PRADO JR., Caio (1994), Formação do Brasil contemporâneo. São Paulo, Brasiliense.

REDFIELD, Robert (1948), "The art of social science". American Journal of Sociology, Chicago, LI, janeiro.

SCHWARZ, Roberto (1992), "Notas do debatedor", in D'INCAO, Maria Angela e SCARABÔTOLO, Eloísa Faria (orgs.), Dentro do texto, dentro da vida. São Paulo, Companhia das Letras.

(1989), A bomenagem na Unicamp. Campinas, editora da Unicamp.

WILLEMS, Emílio (1947), Cunha-tradição e mudança em uma cultura rural do Brasil. São Paulo, Secretária da Agricultura. 


\section{A TRADIÇÃO ESQUECIDA - THE FORGOTTEN TRADITION ESTUDO SOBRE A SOCIOLO- - AN OVERVIEW OF ANTONIO GIA DE ANTONIO CANDIDO}

\author{
Luiz Carlos Jackson
}

Palavras chaves

Pensamento brasileiro; Sociologia; Crítica literária; Sociedade brasileira; Caipira paulista.

Este artigo pretende avaliar a importância de Antonio Candido nas Ciências Sociais brasileiras e a relação entre Sociologia e crítica literária na obra do autor. Nesse sentido, Os Parceiros do Rio Bonito (tese defenfida em 1954 na USP, publicada em livro em 1964) é filiado ao ensaísmo e aproximado de Formação da Literatura Brasileira (1959). Discute-se em que medida Os Parceiros do Rio Bonito deve ser lido como monografia antropológica e produto acadêmico da FFCL/USP e/ou como interpretação mais ampla da formação social brasileira. Nossa hipótese afirma que o livro responde, apesar da evidente distância temática, à mesma preocupação que orientou a redação de Formação da Literatura Brasileira, apontando para uma unidade interna à diversidade da produção intelectual de Antonio Candido, o que a vincula a problemas típicos da tradição ensaística brasileira.

\author{
Luiz Carlos Jackson
}

\section{Keywords} rary Review, Brazilian Society, Caipira Paulista (Paulista Yokel).

This paper intends to evaluate: a) the importance of Antonio Candido for the Brazilian Social Sciences; b) the relationship between Sociology and literary review on the author's work. In this sense, the book Os Parceiros do Rio Bonito (the author's thesis submitted in 1954 at the University of São Paulo, and published in 1964) is affiliated to the Brazilian essayism and considered to be similar to Formação da Literatura Brasileira. The article also wonders whether Os Parceiros do Rio Bonito should be read as an anthropological monograph and/or as a larger interpretation of the Brazilian social formation. The hypothesis of the article assures that the book answers in a different way the same concerns that oriented Formação da Literatura Brasileira, pointing to an internal unity that can be found in Antonio Candido's diverse intellectual production, which binds it to the typical problems of the Brazilian essayistic tradition.
Brazilian Thought, Sociology, Lite-

\section{LA TRADITION OUBLIÉE - ÉTUDE SUR LA SOCIOLOGIE D'ANTONIO CANDIDO}

Luiz Carlos Jackson

\section{Mots-clés}

Pensée brésilienne; Sociologie; Critique littéraire; Société brésilienne; Paysan paulista.

Cet article cherche à évaluer l'importance de Antonio Candido sur les Sciences Sociales brésiliennes et le rapport entre la Sociologie et la critique littéraire dans l'œuvre de l'auteur. Ainsi, Os Parceiros do Rio Bonito (thèse soutenue en 1954 à l'Université de São Paulo et publiée en 1964) est proche de l'essai et de Formação da Literatura Brasileira (1959). Nous discutons dans quelle mesure Os Parceiros do Rio Bonito doit être lu comme une monographie anthropologique et un produit académique de la FFCL/USP et/ou en tant qu'une interprétation plus ample de la formation sociale brésilienne. Notre hypothèse affirme que le livre répond, malgré l'évidente distance thématique, à la même préoccupation qui orienta la rédaction de Formação da Literatura Brasileira, indiquant une unité interne à la diversité de la production intellectuelle de Antonio Candido, ce qui la lie à des problèmes typiques de la tradition brésilienne de l'essai. 